\title{
Characteristics of the elemental compositions of particulate matter at a subway platform using INAA and XRF
}

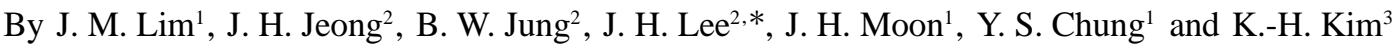 \\ ${ }^{1}$ Department of Nuclear Basic Science, Korea Atomic Energy Research Institute, Daejeon 305-353, Republic of Korea \\ 2 Department of Environmental Engineering, Chungnam National University, Daejeon 305-764, Republic of Korea \\ ${ }^{3}$ Department of Environment and Energy, Sejong University, Seoul 143-747, Republic of Korea
}

(Received December 12, 2009; accepted in revised form December 20, 2010)

Air particulate matter / Metals / Iron / Subway platform / Rail wearing / Neutron activation analysis

Summary. In this study, a total of 21 elements were determined from PM2.5 and PM10 samples collected at one subway station using INAA and XRF. In order to assess the pollution status and distribution characteristics in a subway station, the absolute concentration levels, concentration ratios, and crustal enrichment factors of these elements were analyzed. PM2.5 concentrations in the subway station varied in the range of 24.8 to $72.6 \mu \mathrm{g} \mathrm{m}^{-3}$ (average \pm standard deviation: $42.6 \pm 10.6 \mathrm{\mu g} \mathrm{m}^{-3}$ ), while those of PM10 from 38.0 to $101 \mu \mathrm{g} \mathrm{m}^{-3}\left(67.2 \pm 15.5 \mu \mathrm{g} \mathrm{m}^{-3}\right)$. The relative contribution of elemental components in each particle fraction accounted for about 42 and $44 \%$, respectively. Out of all metals, Fe was predominant to represent about 29 and $27 \%$ of each particle fraction. In contrast, the crustal sources were estimated to contribute to about 3.7 and $2.3 \%$ of the total Fe concentrations, respectively. Thus, one can conclude that considerable quantities of airborne $\mathrm{Fe}$ particles originated mainly from subway sources, probably due to the wearing of the steel products like wheel, rail, brake, etc.

\section{Introduction}

Because of the potential health impact on the human body, the role of airborne particulate matters (APM) particularly as the carrier of many trace metals (such as $\mathrm{As}, \mathrm{Be}, \mathrm{Cd}, \mathrm{Cr}$, $\mathrm{Cu}, \mathrm{Hg}, \mathrm{Mn}, \mathrm{Ni}, \mathrm{Pb}, \mathrm{Sb}, \mathrm{Se}, \mathrm{V}$, and $\mathrm{Zn}$ ) has been emphasized in recent years $[1,2]$. Particulate matter $(\mathrm{PM})$ with aerodynamic diameter equivalent to or less than $2.5 \mu \mathrm{m}$ (PM2.5) can be deposited in the lower respiratory tract because of its permeability. Thus, it is well known that the health effects of aerosol particles are significantly correlated with their quantities in the fine fraction. When the level of APM and/or the content of the specific metals exceed "no observable adverse effect level" (NOAEL), their effects on human health are insidious both over short- and long-term periods [3]. Therefore, sampling and analysis of APM are needed to evaluate the air quality and contamination status.

As most people spend more than $80 \%$ of their time indoors, indoor air quality (IAQ) is an important criterion to

\footnotetext{
*Author for correspondence (E-mail: jinlee@cnu.ac.kr).
}

assess the inhalation conditions of toxic substances. Therefore, monitoring of the PM concentration levels and the associated elemental composition can be used as a practical barometer of IAQ in an indoor environment like a subway station. The contaminants originating from indoor pollution sources as well as various outdoor sources are easily accumulated in indoor environment dissimilar to the outdoor. Especially, because natural ventilation is nearly impossible in a subway station, its air quality can be worsened due mainly to the repetitive movement of subway trains [4]. In fact, high levels of PM have been reported in many previous studies throughout the world [4-10]. However, relatively little is known about the distribution of trace elements including $\mathrm{Fe}$ and/or many toxic elements. Generally, Fe has been well known as the predominant constituent in many subway systems. Nieuwenhuijsen et al. [11] stated that the higher toxicity from inhalation exposure in the metro system may be due to the higher iron content, although Fe is an essential element for human life.

The concentration data of trace metals obtained by longterm monitoring are indispensable for risk assessment and for source identification. Such studies can provide a solid basis for the build-up of various air quality control policies. Hence, an analytical method employed in the determinations of trace elements in APM samples should be sensitive and precise to accurately describe the elemental composition. The source apportionment study can thus be performed using their speciation data (such as carbon, ion, and metal). Although most trace metals ( $\mathrm{Ba}, \mathrm{Br}, \mathrm{Cr}, \mathrm{Cu}, \mathrm{Ni}, \mathrm{Pb}, \mathrm{Se}, \mathrm{V}$, $\mathrm{Zn}$, etc.) constitute only about $1 \%$ of the total particulate mass, they can play a critical role in the identification of diverse source processes. Because large amounts of carbon, ionic components, and major crustal elements are commonly bound to each other in most sources, each source type can be specifically assigned to its tracer [12].

In this study, a total of 60 samples (both PM2.5 and PM10) were collected in the spring and summer seasons of 2009 with two annular denuder samplers at one subway station in Daejeon, Korea. Field campaigns were carried out during a 3 month period in spring (April-May) and summer season (July) in 2009. The measurements were made to cover up to 21 elements in both PM fractions using an instrumental neutron activation analysis (INAA) 
and X-ray fluorescence (XRF). INAA has been favored for many advantages in metal analysis (e.g., high-precision, non-destruction, and multi-elemental capabilities) [13]. In order to assess the pollution status and distribution characteristics of PM-bound metals in a subway station, their absolute concentration level, concentration ratio, and crustal enrichment factor were also evaluated based on our measurement data.

\section{Analytical methods}

\subsection{Sampling}

The collection of all PM samples was made simultaneously with low volume air samplers from one subway station in Daejeon city, Korea. The Daejoen city subway system (approximately 94,000 passengers per day) consists of a single line with about $22.6 \mathrm{~km}$ tunnel path that crosses the central part of the city. The platform was equipped with a screen door to prevent the intrusion of the pollutants from the tunnel. The target sampling station (Yuseong spa station) is surrounded by a highly populated residential and commercial sector in the Yuseong hot spring region.

A total of 60 samples (both PM2.5 and PM10) were collected in parallel from a platform of Yuseong spa subway station during the spring (22 April-5 May) and summer season (1 July-15 July) in 2009. For the collection of both PM fractions, two annular denuder samplers (URG, 3000C model) with polycarbonate filter $(47 \mathrm{~mm}, 0.4 \mu \mathrm{m}$ pore size, Nuclepore) were used. The air flow rates for each sampler were adjusted to $16.7 \mathrm{~L} \mathrm{~min}^{-1}$ and were operated continuously on a 24-h basis. Each filter was placed and weighed in a controlled atmosphere $\left(20^{\circ} \mathrm{C}\right.$ and $50 \%$ relative humidity) for 24-h both before and after exposure to air sampling. These filters were weighed three times with a calibrated microbalance with a readability of $1 \mu \mathrm{g}$ (MT5 model, MettlerToledo Ltd.) of which electrostatic charges are controlled by $\mathrm{a}^{210} \mathrm{Po}$ radioactive source.

\subsection{Elemental analysis}

In the course of this research, a total of 21 trace elemental species were analyzed quantitatively from both PM fractions. The PM-bound concentrations of most elements (Al, As, Ba, Br, Cl, Cr, Cu, Fe, I, In, K, La, Mg, Mn, Na, Sm, Ti, $\mathrm{V}$, and $\mathrm{Zn}$ ) were analyzed by INAA. In case of $\mathrm{Ca}$ and $\mathrm{Si}$, XRF (SEA2220A model, SII SEIKO Instruments Inc.) analysis was made prior to INAA. For the INAA, PM samples were irradiated in the thermal neutron field with the Pneumatic Transfer System (PTS, $\Phi_{\mathrm{th}}=2.95 \times 10^{13} \mathrm{~cm}^{-2} \mathrm{~s}^{-1}$, $\left.R_{\mathrm{Cd}}=250\right)$ at the HANARO research reactor at the Korea Atomic Energy Research Institute (KAERI). For neutron flux monitoring, activation wires were made up of such material as $\mathrm{Au}-\mathrm{Al}, \mathrm{Co}, \mathrm{Fe}$, and $\mathrm{Mn}$ (Reactor Experiments Inc., $\mathrm{R} / \mathrm{X}$ activation wire, $99.99 \%$ purity). The optimum analytical conditions for various operations (e.g., neutron flux, irradiation facilities, irradiation time, cooling time, counting time, etc.) were pre-estimated based on procedures established from our previous studies $[14,15]$. For the determination of short-lived nuclides, the whole filter fraction was irradiated for $1 \mathrm{~min}$. After $\gamma$-ray counting of short-lived nuclides, it was re-irradiated for another $4 \mathrm{~h}$ to determine longlived nuclides. The measurements were carried out using a high purity Ge detector with relative efficiency of $25 \%$. This analytical system has $1.9 \mathrm{keV}$ resolution (FWHM) at $1332 \mathrm{keV}$ of ${ }^{60} \mathrm{Co}$ with the peak to Compton ratio of 45:1. During the measurement of the activated samples, dead time is maintained below $10 \%$. Energy and efficiency calibrations were performed using multi-nuclide reference sources (NEN Products Inc., NES-602, $2.54 \mathrm{~cm}$ diameter disc type) that are certified by the National Institute of Standards and Technology (NIST, USA). A Gamma Vision software (EG\&G ORTEC) was used on the basis of: (1) energy and efficiency calibrations, (2) the acquisition of gamma-ray spectra, and (3) peak analysis. The absolute concentrations of elements were estimated by the absolute approach with an aid of a new calculation-based PC code (e.g., HYPERGAM [16]) with the nuclear data library in which a new PC code is adopted with HYPERMET [17]. The counting losses of both short (such as $\mathrm{Al}$ and $\mathrm{V}$ ) and long half-life species were corrected by the inverse value of the mean decay ratio $\left(F_{\mathrm{m}}\right)$. For instance, the activity of $\mathrm{Al}$ can be computed by $1 / F_{\mathrm{m}}$ value (2.87), while it is negligible for long half-life species.

The elemental concentrations in PM samples, blank filters, and standard samples were determined for quality control purposes under the same analytical conditions. The final elemental concentrations were calculated after the subtraction of analytical blank values in polycarbonate filters used in this study (refer to Table 1). The analytical blank values for each target element were significantly lower than those of samples. Considering that the detectabilities are highly variable between different target elements, the net concentration data (signal) close to the analytical blank (noise) are subject to higher uncertainty. The method detection limit (MDL) was evaluated from blank filter values with a confi-

Table 1. Summary of elemental concentrations in blank polycarbonate filter and the corresponding method detection limit (ng/filter).

\begin{tabular}{lcccc}
\hline & Mean & RSD $(\%)$ & $\mathrm{N}$ & MDL $^{a}$ \\
\hline $\mathrm{Al}$ & 73.2 & 44.6 & 6 & 137 \\
$\mathrm{As}$ & 0.037 & 62.3 & 5 & 0.08 \\
$\mathrm{Ba}$ & 3.1 & 73.5 & 4 & 7.7 \\
$\mathrm{Br}$ & 21.9 & 27.0 & 6 & 33.4 \\
$\mathrm{Ca}$ & 6217 & 1.7 & 5 & 6427 \\
$\mathrm{Cl}$ & 185.0 & 8.5 & 6 & 216 \\
$\mathrm{Cr}$ & 214.3 & 28.2 & 6 & 333 \\
$\mathrm{Cu}$ & 2.3 & 39.2 & 6 & 4.08 \\
$\mathrm{Fe}$ & 256.9 & 53.9 & 4 & 528 \\
$\mathrm{I}$ & 1.0 & 24.8 & 6 & 1.55 \\
$\mathrm{In}$ & 0.006 & 59.4 & 5 & 0.01 \\
$\mathrm{~K}$ & 42.7 & 45.8 & 6 & 81.1 \\
$\mathrm{La}$ & 0.031 & 57.5 & 5 & 0.07 \\
$\mathrm{Mg}$ & 68.9 & 18.7 & 6 & 94.1 \\
$\mathrm{Mn}$ & 1.6 & 37.1 & 5 & 2.79 \\
$\mathrm{Na}$ & 113.2 & 10.4 & 6 & 136 \\
$\mathrm{Si}$ & 15969 & 14.3 & 5 & 20430 \\
$\mathrm{Sm}$ & 0.008 & 74.5 & 4 & 0.02 \\
$\mathrm{Ti}$ & 14.1 & 46.7 & 6 & 27.0 \\
$\mathrm{~V}$ & 0.1 & 24.8 & 6 & 0.18 \\
$\mathrm{Zn}$ & 51.0 & 83.3 & 2 & 134 \\
\hline
\end{tabular}

a: Method detection limit (MDL). 
dence interval of $95 \%$ (e.g., mean $+2 \times$ standard deviation). The MDL is also presented in Table 1.

In this study, the standard reference materials (SRM2783 and 1648) of the NIST were analyzed by the same method as that for the quality control purposes. The elemental concentrations were compared statistically with the certified (or recommended) values. The deviation between the two values generally fell below $5 \%$ for most metal species. As such, the analytical results derived for most elemental components were fairly reliable.

\section{Results and discussion}

\subsection{PM2.5 and PM10 concentration}

The PM2.5 concentrations in the platform area of subway station varied in the range of 24.8 to $72.6 \mu \mathrm{g} \mathrm{m}^{-3}$ with an average ( \pm standard deviation) of $42.6 \pm 10.6 \mu \mathrm{g} \mathrm{m}^{-3}$. In contrast, the PM10 concentration fell in the range of 38.0 to $101 \mu \mathrm{g} \mathrm{m}^{-3}\left(67.2 \pm 15.5 \mu \mathrm{g} \mathrm{m}^{-3}\right)$. The average concentrations of PM10 at subway station did not exceed the PM10 guidelines set for both annual $\left(70 \mathrm{\mu g} \mathrm{m}^{-3}\right)$ and daily intervals $\left(150 \mu \mathrm{g} \mathrm{m}^{-3}\right)$ in Korea. However, the pollution levels of PM2.5 in the study area exceeded the strengthened daily PM2.5 guideline of US National Ambient Air Quality Standard (NAAQS) $\left(35 \mu \mathrm{g} \mathrm{m}^{-3}\right)$ [18]. About $76 \%$ of our daily PM2.5 concentration data were higher than such guideline. The general features of PM distribution are presented in Fig. 1. Differences in concentration levels between PM2.5 and PM10 are statistically significant at $99 \%$ confidence interval. The average concentration ratio of PM2.5/PM10 was estimated to be $0.64 \pm 0.09$ (range: 0.53 to 0.83 ). Furthermore, the daily concentration data for both PM fractions exhibited a moderately strong correlation (correlation coefficient $(r)=0.69, p<0.01)$. These findings reflect that the

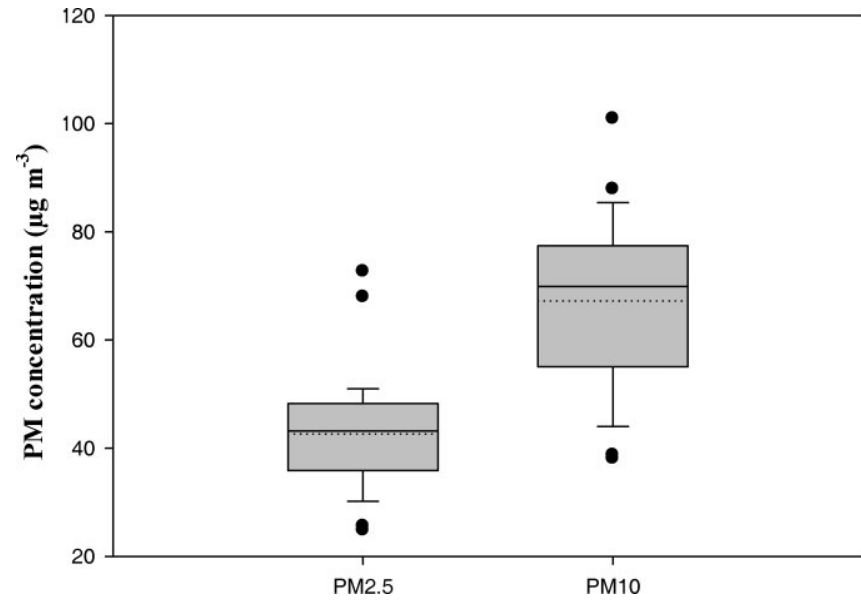

Fig. 1. Absolute concentrations of PM2.5 and PM10 measured in the model subway station.

particle mass in the fine fraction (with anthropogenic origin) should be dominant over its counterpart with crustal origin.

\subsection{Elemental concentration}

Table 2 summarizes PM and the associated elemental concentration data measured from all PM samples collected at our target subway station in Daejeon city, Korea. To describe the distribution patterns of 21 elements, their concentration data were simply evaluated by their magnitude. The results can be grouped arbitrarily into five different categories: 1) $<10^{0} \mathrm{ng} \mathrm{m}^{-3}$ : In, La, and Sm; 2) $<10^{1} \mathrm{ng} \mathrm{m}^{-3}$ : As, Br, I, and $\mathrm{V}$; 3) $<10^{2} \mathrm{ng} \mathrm{m}^{-3}$ : $\mathrm{Cr}$ and Ti; 4) $<10^{3} \mathrm{ng} \mathrm{m}^{-3}$ : $\mathrm{Al}, \mathrm{Cl}$, $\mathrm{Cu}, \mathrm{K}, \mathrm{Mg}, \mathrm{Mn}, \mathrm{Na}$, and $\mathrm{Zn}$; and 5) $>10^{3} \mathrm{ng} \mathrm{m}^{-3}: \mathrm{Ba}, \mathrm{Ca}$, $\mathrm{Fe}$, and $\mathrm{Si}$. The concentrations of $\mathrm{As}, \mathrm{Cr}, \mathrm{Cu}, \mathrm{Mn}$, and $\mathrm{Zn}$ in PM2.5 averaged as $1.57 \pm 0.80,41.1 \pm 7.28,178 \pm 45.3$,

Table 2. Statistical summary of PM2.5 and PM10 concentrations and the associated elemental components at the target subway station. The unit of PM is $\mu \mathrm{g} \mathrm{m}^{-3}$, while all the rest are in $\mathrm{ng} \mathrm{m}^{-3}$.

\begin{tabular}{|c|c|c|c|c|c|c|c|c|c|c|}
\hline & \multicolumn{5}{|c|}{ PM2.5 } & \multicolumn{5}{|c|}{ PM10 } \\
\hline & Mean & $\mathrm{SD}$ & Min & $\operatorname{Max}$ & $N$ & Mean & SD & Min & $\operatorname{Max}$ & $N$ \\
\hline $\mathrm{Al}$ & 286 & 179 & 96 & 860 & 29 & 550 & 260 & 222 & 1111 & 29 \\
\hline As & 1.57 & 0.80 & 0.61 & 3.71 & 29 & 2.16 & 0.90 & 0.91 & 4.88 & 29 \\
\hline $\mathrm{Ba}$ & 705 & 191 & 384 & 1092 & 28 & 1112 & 291 & 492 & 1627 & 29 \\
\hline $\mathrm{Br}$ & 6.18 & 2.77 & 1.82 & 13.4 & 29 & 9.22 & 3.81 & 4.60 & 21 & 26 \\
\hline $\mathrm{Ca}$ & 994 & 277 & 429 & 1535 & 29 & 2130 & 272 & 1567 & 2606 & 29 \\
\hline $\mathrm{Cl}$ & 171 & 68.1 & 84.2 & 358 & 29 & 518 & 244 & 239 & 1237 & 29 \\
\hline $\mathrm{Cr}$ & 41.1 & 7.28 & 27.0 & 58.6 & 29 & 62.2 & 10.5 & 44.0 & 78.6 & 27 \\
\hline $\mathrm{Cu}$ & 178 & 45.3 & 89.6 & 248 & 29 & 291 & 77.6 & 132 & 396 & 29 \\
\hline $\mathrm{Fe}$ & 12165 & 2916 & 5801 & 16683 & 29 & 17969 & 4823 & 7481 & 26158 & 29 \\
\hline I & 2.58 & 1.83 & 0.55 & 8.58 & 29 & 3.72 & 1.93 & 0.82 & 9.27 & 29 \\
\hline In & 0.01 & 0.01 & 0.00 & 0.03 & 27 & 0.02 & 0.01 & 0.01 & 0.05 & 27 \\
\hline $\mathrm{K}$ & 239 & 253 & 10 & 1255 & 29 & 417 & 318 & 107 & 1396 & 29 \\
\hline $\mathrm{La}$ & 0.37 & 0.25 & 0.10 & 1.25 & 29 & 0.68 & 0.35 & 0.17 & 1.53 & 29 \\
\hline $\mathrm{Mg}$ & 161 & 50 & 96 & 296 & 29 & 278 & 84 & 113 & 426 & 27 \\
\hline $\mathrm{Mn}$ & 98.5 & 27.2 & 49 & 144 & 28 & 157 & 45.7 & 67.1 & 239 & 29 \\
\hline $\mathrm{Na}$ & 115 & 70.6 & 35 & 329 & 29 & 235 & 157 & 69.8 & 707 & 29 \\
\hline $\mathrm{Si}$ & 2402 & 864 & 1248 & 4585 & 29 & 5446 & 1061 & 3786 & 8141 & 29 \\
\hline $\mathrm{Sm}$ & 0.04 & 0.04 & 0.01 & 0.24 & 29 & 0.07 & 0.05 & 0.02 & 0.19 & 29 \\
\hline $\mathrm{Ti}$ & 21 & 11 & 5.28 & 47.5 & 29 & 45 & 18.2 & 20.3 & 87.8 & 28 \\
\hline V & 2.40 & 1.09 & 0.89 & 4.98 & 29 & 3.43 & 1.51 & 1.48 & 7.85 & 29 \\
\hline $\mathrm{Zn}$ & 173 & 44.4 & 90.5 & 280 & 29 & 250 & 52.3 & 133 & 364 & 29 \\
\hline PM & 42.6 & 10.6 & 24.8 & 72.6 & 29 & 67.2 & 15.5 & 38.0 & 101 & 29 \\
\hline
\end{tabular}




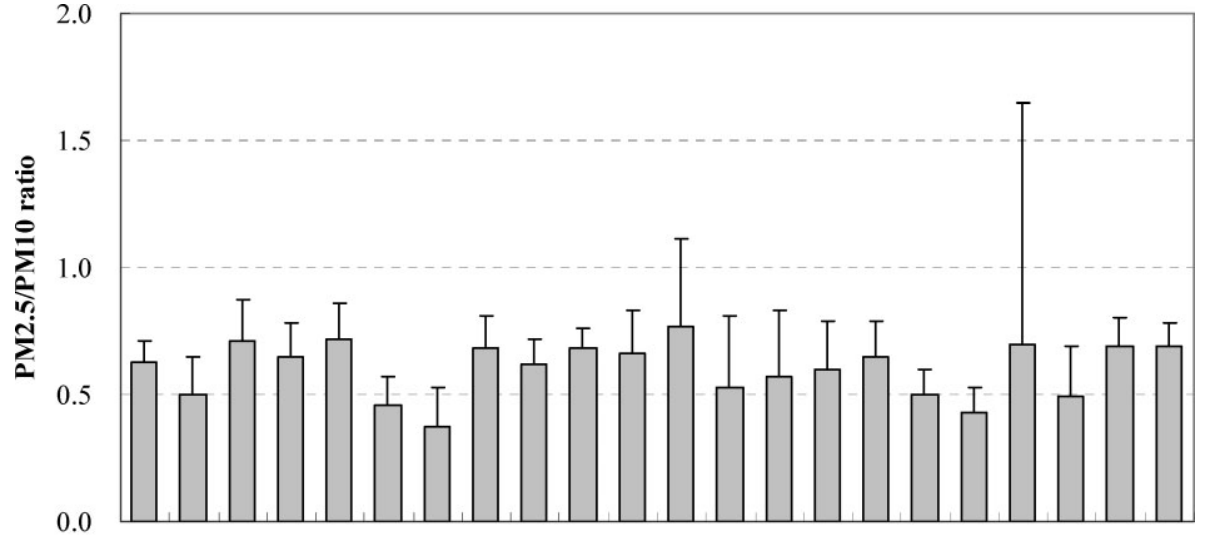

$\mathrm{PM} \mathrm{Al}$ As $\mathrm{Ba} \mathrm{Br} \mathrm{Ca} \mathrm{Cl} \mathrm{Cr} \mathrm{Cu} F e$ I In $\mathrm{K}$ La Mg Mn Na $\mathrm{Si}$ Sm Ti $\mathrm{V}$ Zn
Fig. 2. Average daily elemental concentration ratios between daily of PM2.5 and PM10.
$98.5 \pm 27.2$, and $173 \pm 44.4 \mathrm{ng} \mathrm{m}^{-3}$, respectively, while their PM10 counterparts were $2.16 \pm 0.90,62.2 \pm 10.5,291 \pm$ $77.6,157 \pm 45.7$, and $250 \pm 52.3 \mathrm{ng} \mathrm{m}^{-3}$, respectively.

As shown in Fig. 2, the average PM2.5/PM10 concentration ratios for each element ranged from $0.37(\mathrm{Cl})$ to 0.77 (In) in this study. Concentration ratios of most elements exhibited above 0.6 except for crustal origin ( $\mathrm{Al}, \mathrm{Ca}, \mathrm{K}, \mathrm{Ti}$, and $\mathrm{Si}$ ) and sea salt $(\mathrm{Cl})$. One can thus confirm that elements of crustal origin fell mainly in coarse particle fraction, while those of anthropogenic origin are more dominant in fine particle fraction. This relative pattern observed in our target subway is thus comparable to that of ambient air in certain respects.

To account for the relative contribution of elemental components to the PM mass, the concentrations of 21 elements, determined in this study, were summed up and compared with the mass of the corresponding PM fractions; each fraction accounted for about 42\% (PM2.5) and 44\% (PM10). As such, the relative contribution of elements to PM mass is significantly different between subway and ambient air. The speciation of the measured elements in each PM fraction is shown in Fig. 3. For the clarity, the elements were divided into four groups: 1) Fe; 2) major crustal elements: $\mathrm{Al}$, $\mathrm{Ca}, \mathrm{K}, \mathrm{Mg}$, and $\mathrm{Si}$; 3) minor elements: $\mathrm{Ba}, \mathrm{Cl}, \mathrm{Cr}, \mathrm{Cu}, \mathrm{Na}$, Mn, Ti, and Zn; and 4) trace elements: As, Br, I, In, La, Sm, and V. Major components of PM (e.g., elemental and organic carbon or soluble ions in airborne particles) which were not determined in this study appeared to occupy the remaining $56-58 \%$.

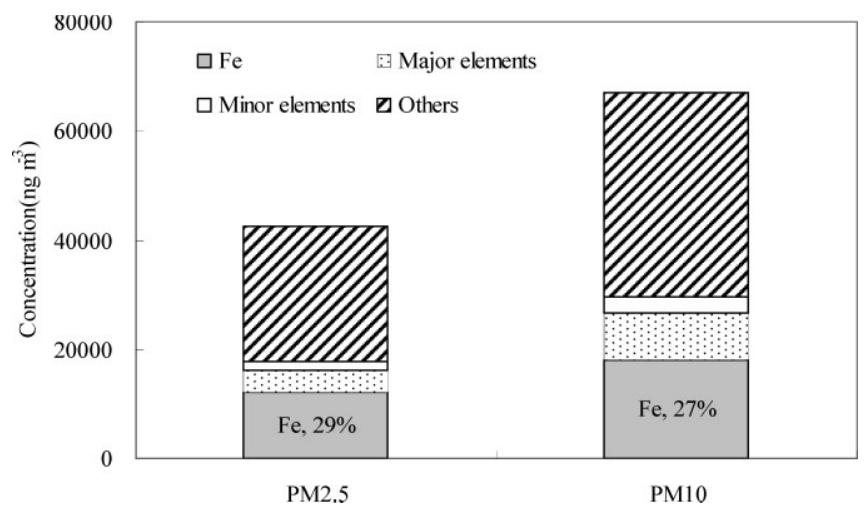

Fig. 3. Comparison of elemental compositions in PM2.5 and PM10 samples.
From the Table 2 data (and Fig. 3), it was found that the concentrations of $\mathrm{Fe}$ in both fractions were substantially larger than all other elements. One may note that $\mathrm{Fe}$ is generally the most abundant element in indoor environment of a subway station, as it can be released by the wearing of steel products [19]. The Fe concentrations in PM2.5 varied in the range of 5.8 to $16.7 \mu \mathrm{g} \mathrm{m}^{-3}$ with average ( \pm standard deviation) of $12.2 \pm 2.9 \mu \mathrm{g} \mathrm{m}^{-3}$, while those in PM10 ranged from 7.5 to $26.2 \mu \mathrm{g} \mathrm{m}^{-3}\left(18.0 \pm 4.8 \mu \mathrm{g} \mathrm{m}^{-3}\right)$. The concentrations of Fe alone accounted for 29 and $27 \%$ of PM2.5 and PM10, respectively, while those of the major crustal elements were about 10 and $13 \%$, respectively. The proportion of other minor and trace elements was significantly lower on the other hand (by about 4\%).

As shown in Fig. 3, the predominant element, Fe tends to occur in the form of magnetite $\left(\mathrm{Fe}_{3} \mathrm{O}_{4}\right)$. Seaton et al. [20] studied the toxicological aspects of PM10 collected in a London subway station; they found that Fe-enriched dust has a cytotoxic and inflammatory potential. Thus, in order to evaluate the relative contribution of anthropogenic sources to the observed Fe levels, its proportion was calculated by the equation shown below [5].

$$
\text { Crustal amount of }(\mathrm{Fe})_{\mathrm{APM}}=\left(\frac{\mathrm{Fe}}{\mathrm{Si}}\right)_{\text {crust }} \times(\mathrm{Si})_{\mathrm{APM}}
$$

Here, $(\mathrm{Si})_{\mathrm{APM}}$ and $(\mathrm{Fe})_{\mathrm{APM}}$ denote the concentrations of $\mathrm{Si}$ and $\mathrm{Fe}$ in $\mathrm{APM}$, while $(\mathrm{Si})_{\text {crust }}$ and $(\mathrm{Fe})_{\text {(crust) }}$ represent their global average concentrations in earth crust [21]. The contributions of crustal sources to the observed Fe levels were estimated as 3.7 (PM2.5) and 2.3\% (PM10) of the total Fe. Thus, one can conclude that considerable amount of airborne Fe in subway stations was mainly derived by the wearing of steel products (e.g., wheel, rail, and brake).

Typically, $\mathrm{Ba}$ is an element added to the lubricating oil to prevent smoke and engine abrasion of diesel vehicles [22]. Thus, it has been used as one of the marker species of road dust in ambient air [12]. It is also known that $\mathrm{Ba}$ (and $\mathrm{Mn}$ ) can also be enriched in subway station $[11,19,20,23]$. The pollution level of $\mathrm{Ba}\left(1112 \mathrm{ng} \mathrm{m}^{-3}\right)$ in PM10 was significantly higher (about 26 times) than that measured at an industrial area $\left(43.4 \mathrm{ng} \mathrm{m}^{-3}\right)$ in the same city [12]. The relative enrichment of Mn was not observed in the subway station, which is suspected to arise from insignificant role of subway sources relative to outdoor ones (e.g., antiknock agent in gasoline vehicles) [23]. 


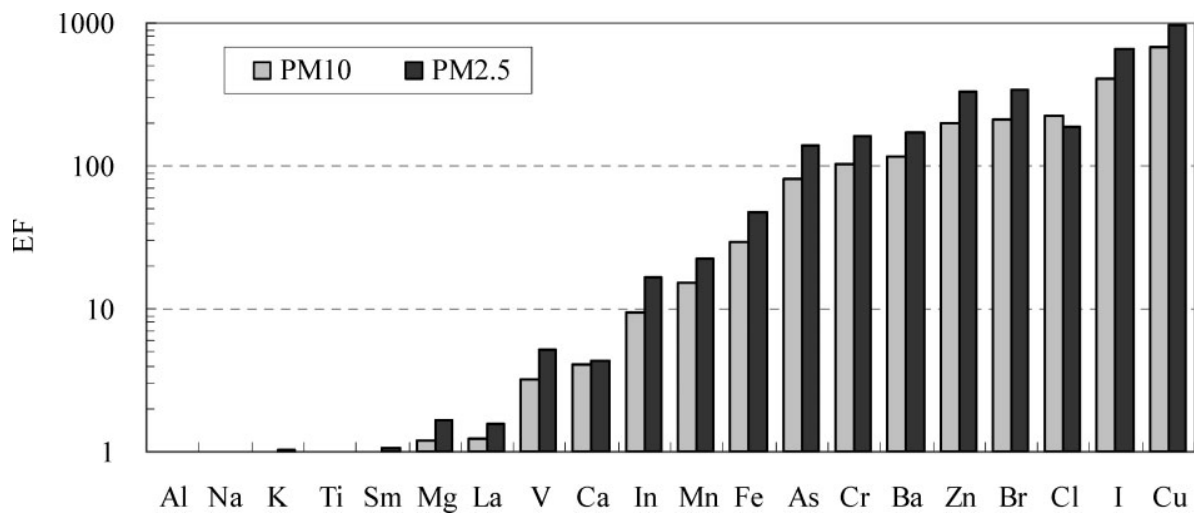

Fig. 4. Crustal enrichment factor (EF) values for all elements in PM10 and PM2.5 fractions.

The concept of enrichment factor (EF) can be introduced to help distinguish some elements with well-defined sources (e.g., $\mathrm{Si}$ as the major component of the earth's crust) from other ones with different origins [21]. By comparing the concentration of a target element to a reference element like $\mathrm{Si}\left[\mathrm{EF}=(\mathrm{X} / \mathrm{Si})_{\mathrm{PM}} /(\mathrm{X} / \mathrm{Si})_{\text {crust }}\right]$, one can evaluate the extent of enrichment for a given element. Because $\mathrm{Si}$ is the most abundant element in the crustal composition or is affected less significantly by anthropogenic sources, it was selected as a reference element in this study. It is acknowledged that $\mathrm{EF}$ values of elements are associated with some degree of uncertainty due to the natural variation of the crustal composition. However, one may assume that the EF value larger by an order of magnitude than unity can signal the potent role of anthropogenic origin $[24,25]$. By setting the arbitrary EF value of 10 , we attempted to sort out such a signal from several metals (e.g., As, Ba, Br, Cl, Cr, Cu, Fe, I, Mn and $\mathrm{Zn}$ ) for both PM fractions. The EF values for almost all elements in the PM10 samples were lower than those in PM2.5 samples. It was noteworthy that most elements with higher $\mathrm{EF}$ values (e.g., As, $\mathrm{Br}, \mathrm{Cl}, \mathrm{Cu}, \mathrm{I}$, and $\mathrm{Zn}$ ) are typically classified as the key components of major anthropogenic processes with different characteristics such as industrial activities, fossil fuel combustion, and high traffic activities. Because $\mathrm{Ba}, \mathrm{Cr}, \mathrm{Fe}$, and $\mathrm{Mn}$ can be generally classified into elements of crustal origin, their relative enrichment in subway station should be accounted for by the resuspension of crustal particulates through incoming passengers (penetration of outdoor APM) as well as anthropogenic sources within subway station (steel friction of railway and wheel).

\section{Conclusion}

In this study, PM2.5 and PM10 samples were collected at one subway station in Daejeon, Korea, and the concentrations of the associated elements (up to 21) were determined using INAA and XRF. Based on our measurement, the pollution status and the distribution characteristics of diverse metal components in subway particles were evaluated in many respects. The contents of analytical blank and MDL for target elements were significantly lower than their average content determined from the actual samples. If one considers the fact that the relative error of SRM samples (for quality control) generally fell below $5 \%$ for most metal species, the analytical results derived for most elemental components in PM samples were fairly reliable.
The PM2.5 concentrations in the subway station varied in the range of 24.8 to $72.6 \mu \mathrm{g} \mathrm{m}^{-3}$ with average ( \pm standard deviation) of $42.6 \pm 10.6 \mathrm{\mu g} \mathrm{m}^{-3}$. The PM10 concentrations were seen at moderately enhanced levels from 38.0 to $101 \mu \mathrm{g} \mathrm{m}^{-3}$ with average ( \pm standard deviation) of $67.2 \pm 15.5 \mu \mathrm{g} \mathrm{m}^{-3}$. The pollution levels of PM2.5 in the target subway exceeded the strengthened US NAAQS daily PM2.5 guideline $\left(35 \mu \mathrm{g} \mathrm{m}^{-3}\right) ; 76 \%$ of our daily PM2.5 data are higher than such guideline. Unlike the case of ambient air, the relative contribution of elemental components was significant enough to account for about 42 and $44 \%$ of PM mass in PM2.5 and PM10 fractions, respectively. The proportion of $\mathrm{Fe}$ in those PM fractions were apportioned to 29 and $27 \%$, respectively. However, the crustal sources were estimated as 3.7 and $2.3 \%$ of the total $\mathrm{Fe}$ concentrations, respectively. Thus, one can conclude that airborne $\mathrm{Fe}$ in subway station should come mainly from the wearing of steel products in subway systems (e.g., wheel, rail, and brake), regardless of particle size. Evaluation of elemental concentration ratios led us to conclude that crustal elements are still associated with coarse particle fraction, while Fe and most elements with anthropogenic origin are tightly linked to fine particle fraction produced in the subway station. Data from this study can be used further to apportion different sources and to assess health risk so that one can establish or improve policies and strategies for an indoor air quality management in the public transportation system.

Acknowledgment. This research was supported by the Nuclear R\&D Program by the Ministry of Science and Technology, Republic of Korea.

\section{References}

1. Natusch, D. F. S., Wallace, J. R., Evans Jr., C. A.: Toxic trace elements: preferential concentration in respirable particles. Science 183, 202 (1974).

2. Dockery, D. W., Pope III, C. A.: Acute respiratory effects of particulate air pollution. Annu. Rev. Publ. Health 15, 107 (1994).

3. Lim, J. M., Lee, J. H., Moon, J. H., Chung, Y. S., Kim, K. H.: Airborne PM10 and metals from multifarious sources in an industrial complex area. Atmos. Res. 96, 53 (2010).

4. Cheng, Y. H., Lin, Y. L., Liu, C. C.: Levels of PM10 and PM2.5 in Taipei Rapid Transit System. Atmos. Environ. 42, 7242 (2008).

5. Salma, I., Psfai, M., Kovács, K., Kuzmann, E., Homonnay, Z., Posta, J.: Properties and sources of individual particles and some chemical species in the aerosol of a metropolitan underground railway station. Atmos. Environ. 43, 3460 (2009).

6. Chan, L. Y., Lau, W. L., Zou, S. C., Cao, Z. X., Lai, S. C.: Exposure level of carbon monoxide and respirable suspended partic- 
ulate in public transportation modes while commuting in urban area of Guangzhou, China. Atmos. Environ. 36, 5831 (2002).

7. Aarnio, P., Yli-Tuomi, T., Kousa, A., Mäkelä, T., Hirsikko, A., Hämeri, K., Räisänen, M., Hillamo, R., Koskentalo, T., Jantunen, M.: The concentrations and composition of and exposure to fine particles (PM2.5) in the Helsinki subway system. Atmos. Environ. 39, 5059 (2005).

8. Grass, D. S., Ross, J. M., Family, F., Barbour, J., Simpson, H. J., Coulibaly, D., Hernandez, J., Chen, Y., Slavkovich, V., Li, Y., Graziano, J., Santella, R. M., Brandt-Rauf, P., Chillrud, S. N.: Airborne particulate metals in the New York City subway: A pilot study to assess the potential for health impacts. Environ. Res. 110, 1 (2010)

9. Murruni, L. G., Solanes, V., Debray, M., Kreiner, A. J., Davidson, J., Davidson, M., Vázquez, M., Ozafrán, M.: Concentrations and elemental composition of particulate matter in the Buenos Aires underground system. Atmos. Environ. 43, 4577 (2009).

10. Kim, K. Y., Kim, Y. S., Roh, Y. M., Lee, C. M., Kim, C. N.: Spatial distribution of particulate matter (PM10 and PM2.5) in Seoul Metropolitan Subway stations. J. Hazard. Mater. 154, 440 (2008).

11. Nieuwenhuijsen, M. J., Gmez-Perales, J. E., Colvile, R. N.: Levels of particulate air pollution, its elemental composition, determinants and health effects in metro systems. Atmos. Environ. 41, 7995 (2007)

12. Lim, J. M., Lee, J. H., Moon, J. H., Chung, Y. S., Kim, K. H.: Source apportionment of PM10 at a small industrial area using positive matrix factorization. Atmos. Res. 95, 88 (2010).

13. Salma, I., Zemplén-Papp, E.: Instrumental neutron activation analysis for studying size-fractionated aerosols. Nucl. Instrum. Methods Phys. Res. A 435, 462 (1999).

14. Lee, J. H., Lim, J. M., Kim, K. H.: Instrumental neutron activation analysis of elemental compositions in particles collected during Asian dust period. J. Radioanal. Nucl. Chem. 263, 667 (2005).
15. Lim, J. M., Lee, J. H., Chung, Y. S.: The distribution characteristics of trace elements in airborne particulates from an urban industrial complex area of Korea using instrumental neutron activation analysis. Nucl. Eng. Technol. 37, 503 (2005).

16. Park, C. S., Choi, H. D., Sun, G. M., Whang, J. H.: Status of developing HPGE r-ray spectrum analysis code HYPERGAM. Prog. Nucl. Energ. 50, 389 (2008)

17. Phillps, G. W., Marlow, K. W.: A fast approximation to the complementary error function for use in fitting gamma-ray peaks. Nucl. Instrum. Methods 137, 525 (1976).

18. US EPA, National Ambient Air Quality Standard for PM2.5. http://www.epa.gov/air/criteria.html (2009).

19. Johansson, C., Johansson, P. A.: Particulate matter in the underground of Stockholm. Atmos. Environ. 37, 3 (2003).

20. Seaton, A., Cherrie, J., Dennekamp, M., Donaldson, K., Hurley, J. F., Tran, C. L.: The London underground: dust and hazards to health. Occup. Environ. Med. 62, 355 (2005).

21. Taylor, S. R., McLennan, S. M.: The continental crust: Its composition and evolution, an examination of the geochemical record preserved in sedimentary rocks. Blackwell, Oxford (1985), $312 \mathrm{pp}$.

22. Monaci, F., Bagagli, R.: Barium and other trace metals as indicators of vehicle emissions. Water Air Soil Poll. 100, 89 (1997).

23. Boudia, N., Halley, R., Kennedy, G., Lambert, J., Gareau, L., Zayed, J.: Manganese concentrations in the air of the Montreal (Canada) subway in relation to surface automobile traffic density. Sci. Total Environ. 366, 143 (2006).

24. Kim, K. H., Lee, J. H., Jang, M. S.: Metals in airborne particulate matter from the first and second industrial complex area of Taejon city, Korea. Environ. Pollut. 118, 41 (2002).

25. Senaratne, I., Shooter, D.: Elemental composition in source identification of brown haze in Auckland, New Zealand. Atmos. Environ. 38, 3049 (2004). 